\title{
Exit or Developmental Impact? The Role of 'Graduation' in Social Protection Programmes
}

\author{
Michael Samson*
}

\begin{abstract}
The framework developed in this article illustrates how social protection with a developmental approach can deepen socioeconomic impact at individual and household level and effectively address apprehension over dependency. The starting point examines various definitions of 'graduation' within a social protection context - as exit from poverty, or from the social protection system, or alternatively as a process of continually strengthening household developmental outcomes. Appropriately designed and effectively implemented, a 'graduation' approach can sustainably promote dynamic outcomes, with inclusive economic expansion reinforcing poverty reduction, which in turn contributes to further growth and development. These micro-oriented initiatives will likely work best when embedded within a broader macro development framework that integrates and strengthens the range of social and economic policy instruments implemented by government. This article maps out a path for policymakers aiming to strengthen the pro-poor and inclusive economic growth and development impacts of social protection by incorporating a graduation approach.
\end{abstract}

\section{Introduction}

The past two decades have seen developing countries around the world rapidly adopting a range of social protection programmes that enable individuals and households to confront risk and adversity and ensure at least a minimum standard of dignity and wellbeing. In Africa the number of social cash transfer programmes has increased tenfold - from 25 in 2000 (in nine countries) to 245 in 2012 (in 41 countries) (Garcia and Moore 2012). A large number of national policy frameworks include direct benefits to provide for basic needs and insurance-based mechanisms, which aim to prevent households from further declining into poverty. Both of these kinds of instruments can also promote economic wellbeing. Over the past several years, a number of policymakers and programme implementers have constructed a path that emphasises the promotive aspect of social protection policy, strengthening the capacities of beneficiaries to build more sustaining and sustainable livelihoods. This policy direction, which sometimes combines an integrated cross-sectoral developmental approach with key elements of a social protection approach, is often termed the 'graduation approach' to social protection - and other times referred to as a track to the dynamic deepening of developmental impact - a remedy for the amorphous syndrome of 'dependency' that some fear.

This article examines an intersection of views on exit from poverty and from social protection programmes, as well as on the development impact of these interventions - views that are linked to the idea of 'graduation' emerging in different contexts. The discussion contrasts two approaches to exit strategies with an alternative developmental model. The analysis focuses on a framework that links both micro and macro strategies for deepening developmental impact, drawing on BRAC's successful model and the development planning approach for social protection identified in a number of developing countries around the world.

Concerns over dependency have worried policymakers since the first days of social protection. The fear that small cash payments to very poor households might undermine labour 
incentives has motivated rigorous targeting approaches and sometimes arbitrarily limited the duration of benefits for some programmes. The preoccupation with dependency has roots in at least one economic theory - since social protection enables households to survive in the face of limited livelihoods opportunities - the 'reservation wage' model of the labour market argues that this will lower the cost of not working and potentially reduce labour market activity. Alternative theories - including 'efficiency wage' and risk management models - suggest that social protection may improve labour market engagement, fostering development rather than dependency. Though social protection mainly aims to tackle vulnerability, poverty and social exclusion, the incorporation of what are sometimes termed 'graduation strategies' can contribute to household social and economic development, as well as to pro-poor and inclusive economic growth.

\section{Alternative views on programme exit, graduation and developmental impacts}

A review of social protection programmes around the world (Samson 2012) has identified three different models of exit: (1) exogenous,

(2) endogenous and (3) developmental. Exogenous exit does not depend on a participant's poverty status - it usually involves a decline in benefits after a certain period of time or alternatively a time limit on how long a participant remains in the programme. Exit does not depend on a participant's behaviour or economic status, but rather on factors such as age or time-inprogramme which participants cannot influence (hence the characterisation as 'exogenous'). As a result, exogenous exit approaches do not tend to create perverse incentives that undermine developmental outcomes. But they also often do not have the flexibility to address idiosyncratic vulnerabilities. Examples of programmes with exogenous exit approaches include South Africa's Child Support Grant (with exit on a participant's eighteenth birthday), social pension programmes around the developing world (with exit upon the death of the participant), and a number of public works programmes in Africa which limit participation to a fixed six months of employment.

The endogenous graduation approach involves a re-targeting process based on socioeconomic success criteria. Some approaches will include dynamic re-entry points for those suffering shocks, but others have no provisions to address changes in circumstances after exit. Endogenous graduation is more adapted to the specific vulnerabilities of participants (compared to exogenous exit), since participants who are unable to lift themselves out of poverty continue with social protection support. However, this sensitivity can create perverse incentives to remain below the 'graduation threshold', particularly if the programme has no provision for re-entry in the face of subsequent shocks. Exit is 'endogenous' in the sense that an individual's or household's behaviour is influenced by the programme benefit and in turn influences the duration of the benefit. For example, social cash transfer programmes in Zambia and Malawi have grappled with the challenge of re-targeting, which requires terminating benefits for beneficiaries who have improved their economic circumstances to the extent that they no longer require the programme. However, some households who have lost their benefits due to re-targeting have subsequently suffered shocks that have reversed their gains, but they have been unable to re-access programme benefits. ${ }^{1}$

The third approach can be referred to as developmental graduation, and does not necessarily involve exit from the programme.

Developmental graduation programmes often provide comprehensive and integrated benefits that create opportunities for human capital and other productive investment, livelihoods activities and employment. In other cases these programmes offer supplementary opportunities for programme participants alongside or following traditional social protection benefits, including employment creation and livelihoods promotion projects, life skills and vocational training and microfinance (savings and/or credit) services. One of the most frequently referenced examples of developmental graduation is BRAC's Challenging the Frontiers of Poverty Reduction (GFPR) programme, in part because of its relatively large scale and its success in achieving developmental impact. While the CFPR programme benefits are offered for a fixed duration, the impact tends to grow over time, even after the completion of the direct intervention (Samson 2013). BRAC's model has been applied in a number of different contexts around the developing world, with varying degrees of success. 
The focus on the concept of 'graduation', however, sometimes obscures the more meaningful impacts that developmental and integrated social protection/livelihoods interventions generate. A narrow view of graduation programmes that focus on exit may ignore the key objective of promoting dynamic developmental impacts that enable households to progressively lift themselves out of poverty. A limited scope for social protection may fail to effectively tackle poverty and vulnerability if they do not support more comprehensively household demand for broad developmental impacts. The integration of social protection within a broader developmental framework better enables the system to reduce poverty and vulnerability while promoting other pro-poor and inclusive outcomes.

Graduation as 'dynamic deepening of developmental impact' is sometimes referred to as 'graduation without exit'. ${ }^{2}$ Offering a social protection programme with this sort of graduation mechanism can not only reduce poverty and vulnerability, but also expand a poor household's access to labour markets, contribute to a sustainable livelihood, and aid human capital development. At a national level, social protection can build social cohesion, help countries deal with economic shocks, and can enable a government to put in place pro-poor and inclusive economic reforms. There is no need to terminate benefits that contribute broadly to social and economic development, just as there is no need for society to 'graduate' from reliance on bridges, highways and other productive infrastructure. Some programmes, however, have no developmental intent: social pensions, for example, address the rights of older people to income security and often yield broad-based developmental outcomes. Attempts to design them for maximal developmental impacts would compromise their main purpose. Other programmes, however, aim to tackle chronic poverty directly. In these cases, policymakers may choose design features that strengthen developmental impacts.

For programmes that have developmental objectives, two types of considerations affect the likelihood of achieving the dynamic deepening of developmental impact. At a micro-level, key design features promote developmental impact. First, benefits must be both reliable and of sufficient size to support developmental outcomes. Programme design must strengthen livelihood promotion, making developmental impacts a priority. This requires adapting key design features to the social context of poverty. What works in Bangladesh might not work in Ethiopia. The key micro challenge is identifying a mix of design elements that generate developmental impact. In addition to micro factors, successful developmental impact requires an enabling macro climate. Chronic and structural unemployment creates serious bottlenecks, and in general poor market performance undermines opportunities for livelihoods promotion. Challenges in the public sector likewise can weaken developmental impact, particularly if the public provision of human capital services - especially education and health care - is weak. Even when other macro conditions are supportive, developmental impact is threatened by a high prevalence of shocks that threaten the livelihoods of poor households.

A number of challenges complicate the objective of achieving developmental impact. First, most 'graduation' models require rigorous (or 'heavy') forms of targeting, aiming to reach the very poorest using community-based approaches or other mechanisms with often high direct and indirect costs. The expensive up-front costs limit the potential of more universal approaches. Second, the complexity of livelihoods development requires an abundance of skilled programme implementers, stretching the government's capacity to scale programmes up nationally. Third, since the programmes can generate important macro-level effects, simply scaling up a model that is successful at microlevel may backfire. For example, an approach that depends on marketing dairy products produced through a livestock intervention may flood local markets, depressing prices and undermining success.

This article makes the case that the ideal environment for deepening developmental impact combines both micro and macro initiatives. One of the best examples that addresses the micro concerns is BRAC's CFPR programme, which has lifted hundreds of thousands of households out of extreme poverty and demonstrates developmental impacts that increase over time, even after the end of programme benefits. Experience applying this model to other countries, however, demonstrates 


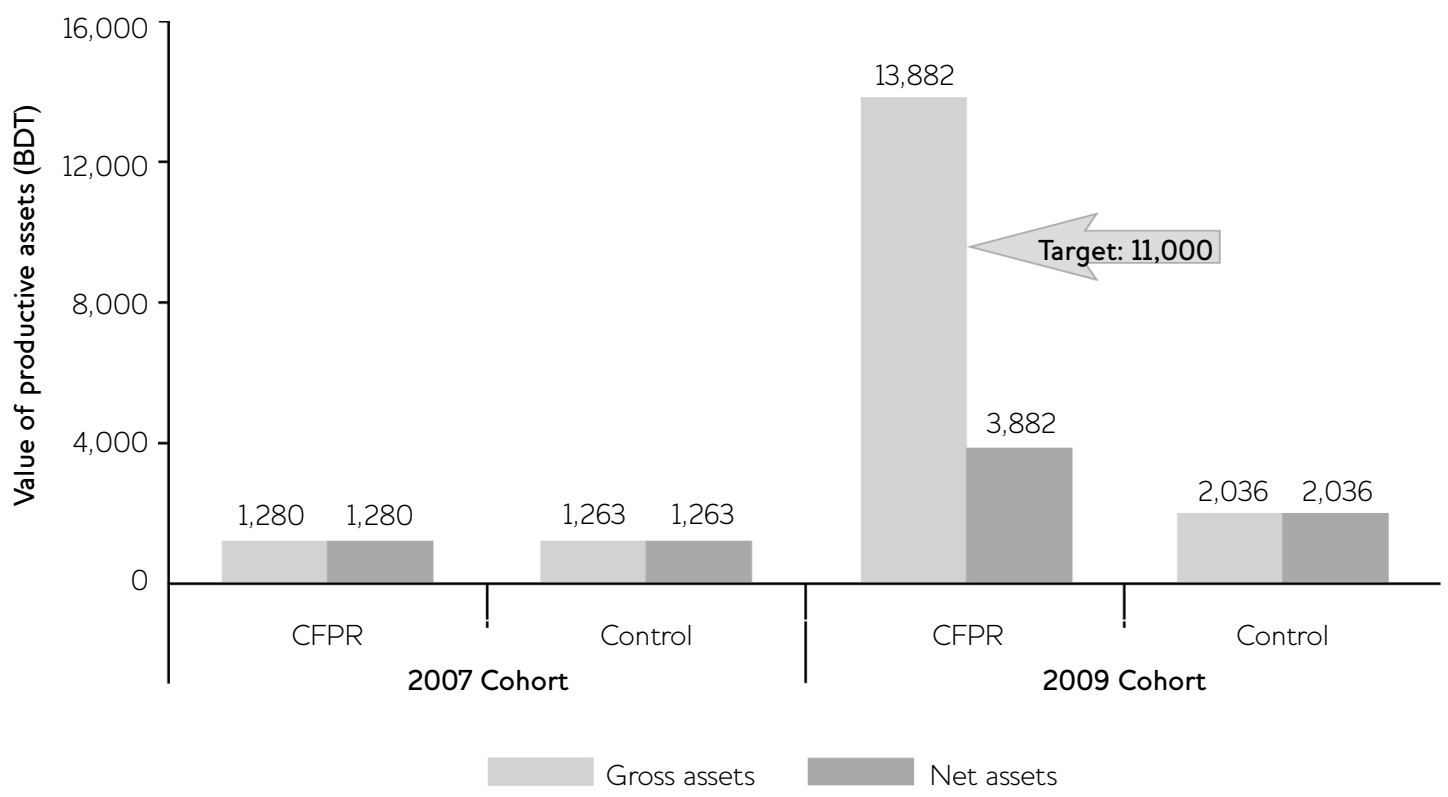

Source Author's calculations with data from Das and Shams (2011).

that key design features do not simply translate to other contexts. The macro dimension is important. Experience in Latin America and Africa suggests that the broad range of complementary programmes implemented in step with social protection significantly determine developmental outcomes. This article goes further, and argues that the development planning approach - which integrates social protection policies and programmes into the broader planning framework - can complement micro-level design features to dynamically deepen developmental impact - that is, to better enable 'graduation' in a developmental sense.

\section{Promoting developmental impact through micro-level design: the case of BRAC's CFPR programme and its global applicability}

BRAC, one of the world's largest nongovernmental organisations (NGOs), implements a well-known developmental social protection programme that increasingly influences global best practices. The CFPR programme's theory of change holds that ultra-poor households will lift themselves out of poverty by building their productive asset base, thus supporting sustainable income-generating activities. The two-year intervention begins with a selection process to identify very poor female-headed households that can effectively utilise programme resources. Once identified, women participating in the programme benefit from human capital services, training in livelihoods skills, cash transfers, access to savings services and then the transfer of a productive asset. Within two years, the participant exits the programme, but BRAC continues to monitor the household to map the progress across a range of developmental indicators. While BRAC uses a mechanism of exogenous exit, the programme more importantly designs for an ongoing developmental impact and succeeds in achieving this.

BRAC's success results from its effective management of the inherent challenges discussed above. BRAC's targeting approach demonstrates an evolved methodology that reflects sensitivity to community concerns and has adapted to previous design bottlenecks. BRAC maximises value-for-money by employing human resources from the local communities it serves, sustaining a competitive cost structure while benefiting from enhanced knowledge of the local context. BRAC's model diversifies livelihoods strategies, offering participants a range of options that reduces the macro-level risks posed by over-capacity. In particular, BRAC's flexible approach benefits from learning-by-doing, with dedicated managers avoiding dogmatic traps and continually progressing through evidence-informed improvements. 


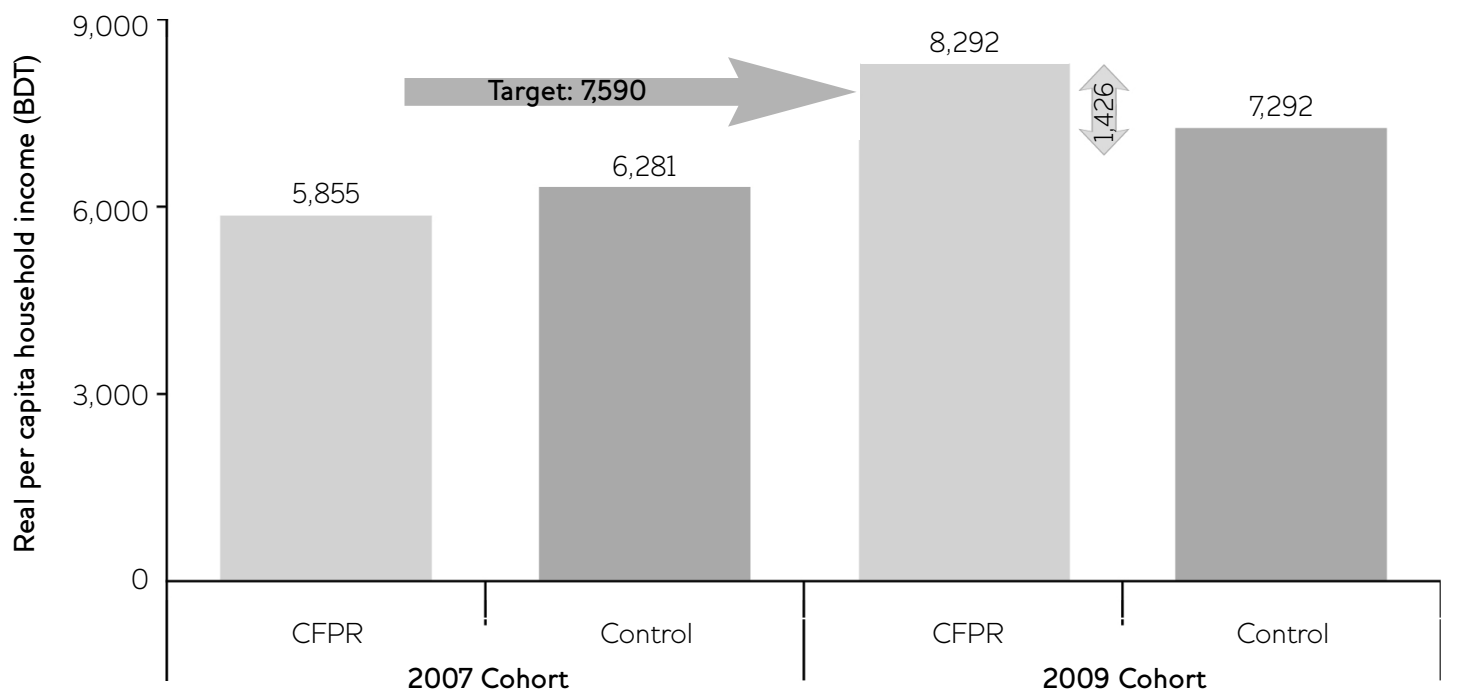

Source Author's calculations with data from Das and Shams (2011).

Figure 1 reports the results of a randomised controlled trial evaluation of the CFPR programme. It shows that two years after recruitment into the programme, the real value of participants' non-land productive assets ('gross assets' in Figure 1) in the component serving the poorest households increased by an average of 1,000 per cent. This improvement well exceeded the programme's initial outcome target. The control group's assets had also increased - however only by an average of 61 per cent. The programme's 'attributable impact' of Bangladesh Taka (BDT) 11,829 represents an increase of 824 per cent over the programme participants' average asset holdings prior to participation in the programme.

One indication of programme impact and valuefor-money can be drawn from further analysis of these impacts. If the value of the actual assets transferred by the GFPR programme is excluded from the calculation of total non-land assets owned by the participants, the value of what might be termed 'net assets' had increased by an average of 200 per cent. This substantially exceeds the control group's increase of 61 per cent, and the programme's 'attributable impact' on 'net assets' was 43 per cent. The fact that households are able to generate increases in the value of assets, in addition to the asset transfers, faster than those in the control group, demonstrates that participants are not dependent on the programme but rather are increasingly self-reliant, providing a strong indication of the sustainability of the programme.

The ability of these additional productive assets to lift households out of poverty can be measured in part by the increase in household incomes of programme participants. Figure 2 demonstrates the economic impact of the programme.

Participating households received a much higher per capita real income - BDT8,292 per year measured in real 2007 purchasing power terms, comfortably exceeding the programme target of BDT7,590.

However, the average real income of the control group members also increased substantially, to BDT7,292 in real purchasing power terms. The difference-in-differences measure of attributable programme impact can be calculated as an increase in per capita real income of BDT1,426, or 24 per cent over two years. This represents a substantial impact, which is greater than that realised in other graduation-oriented programmes around the world.

The sustainability of the CFPR programme can be measured by the continuing increases in developmental impact. Figure 3 presents an index of developmental outcomes ${ }^{3}$ for three groups of participants recruited into the programme in successive years from 2007 to 2009: 


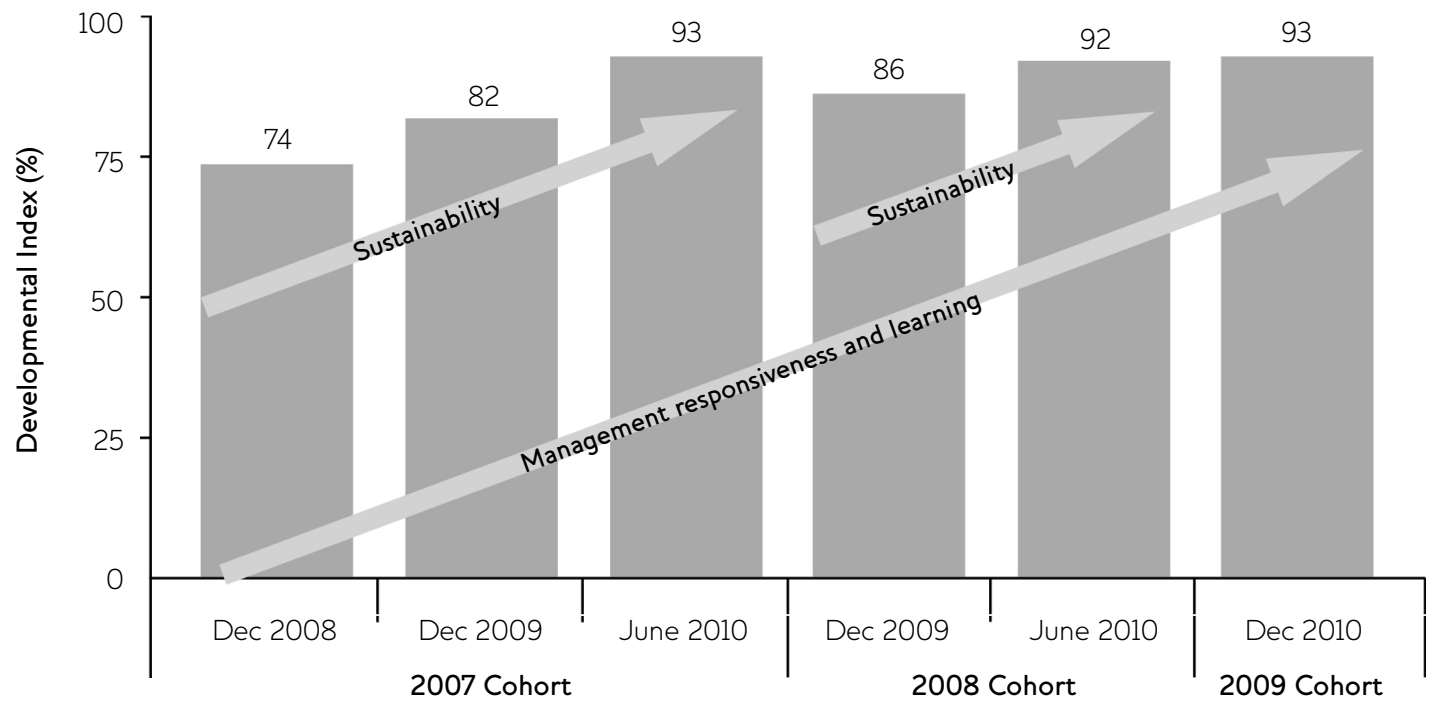

Source Author's own calculations based on analysis of data from BRAC's MIS. (Note that programme benefits for the 2007 cohort ended in December 2008, for the 2008 cohort in December 2009 and for the 2009 cohort in December 2010. The first bar in each 'segment' represents the endpoint of benefit receipt.)

- For the 2007 cohort, the development index was assessed upon their completion of the programme in December 2008, a follow-up assessment in December 2009, and a subsequent interim assessment in June 2010.

- For the 2008 cohort, the development index was assessed upon their completion of the programme in December 2009, and an interim follow-up assessment in June 2010.

- For the 2009 cohort, the development index was assessed upon completion of the programme in December 2010.

The figure reports the results of the analysis. For the 2007 cohort, the initial assessment in December 2008 yielded a development index (sometimes referred to as a 'graduation' rate) of 74 per cent, well below the 90 per cent target. The following year, this had improved to 82 per cent and it exceeded the target by June 2010 , when it reached 93 per cent. The 2008 cohort demonstrated a higher initial development index upon programme completion, achieving a rate of 86 per cent which rose to 92 per cent in the following year, also exceeding the target. The December 2009 cohort demonstrated even greater progress compared to the initial point for previous cohorts, achieving a 93 per cent development index upon programme completion.
This data supports two important implications. First, the fact that cohorts consistently improve their development index suggests that the programme is working in a sustainable manner. Even after the direct asset-building and assetsupporting benefits end, programme participants are able to continue to increase their productive assets, improve their livelihoods activities and achieve developmental outcomes. In-depth interviews and focus group discussions provided evidence that the programme's model was directly responsible for improving people's lives, attitudes and economic opportunities. Second, the fact that the initial end of programme graduation rates improved consistently from 2008 to 2010 suggests that the CFPR programme proactively responded to challenges it encountered, learned appropriate lessons and continued to improve programme design and implementation in order to strengthen CFPR success, as depicted by the increasing proportion of beneficiary households who have achieved the graduation criteria both within cohorts over time (representing the sustainability and resilience of impact) and for successive cohorts (representing management responsiveness and learning-by-doing).

The main question for the CFPR programme from a global development perspective is the extent to which the model can be applied to 
different contexts in other countries. Similar approaches have been adopted within Bangladesh, with a high degree of success, and have highlighted the importance of alternative design features, particularly savings and training. ${ }^{4}$ Applications to other country contexts are still in progress, with varying degrees of success to date. The Ford Foundation together with Consultative Group to Assist the Poor (CGAP) have implemented a coordinated set of pilots building on the GFPR model in Ethiopia, Ghana, Haiti, Honduras, India, Pakistan, Peru and Yemen. While they all started as small pilots ranging between 150 and 1,000 participants, a number are already scaling up. Nearly all include both randomised controlled trial impact assessments along with qualitative evaluations. Initial results show significant impacts in terms of improved food security (such as a 50 per cent decline in food insecurity in Haiti, and a 25 per cent increase in consumption in India), increased income and savings in India and improved health access and outcomes. ${ }^{5}$ Because these programmes are relatively young, more robust and credible evidence will require additional phases of programme evaluation.

The important lesson from the initial evaluations of these pilots is the value of integrating impact assessments across a range of country contexts. BRAC's CFPR programme provides no magic bullet for developmental impact. The model contributes significant insight - but the challenges of tackling extreme poverty and cultivating developmental impact vary substantially from country to country. Integrated evaluations enable researchers to identify what works best in different contexts, adding significant value to multi-country studies.

\section{Promoting developmental impact through macro-level linkages: the role of the development planning framework for social protection}

The conventional approach to 'graduation' involves designing micro components within social protection programmes, strengthening the developmental impact of the benefits. However, social protection schemes will also need to address macro considerations in order to have appropriate developmental impacts. Sabates-Wheeler and Devereux (2013) highlight factors of the macroeconomic environment that may constrain 'graduation' components of social protection programmes or their developmental impacts more broadly. Specifically, market conditions, scale of programme coverage, and environmental context can have significant effects on the impacts of social protection. This article presents the case that social protection interventions that operate at household and community levels work best when integrated within a macro-level policy environment that strengthens developmental impact. Policies that strengthen social protection's natural tendency to promote livelihoods and foster pro-poor and inclusive economic growth and development yield the greatest impact when coordinated with a range of government interventions within a larger planning framework. With a supportive macroeconomic climate, grants enable households to invest in more sustaining livelihoods, as this additional income can be invested in activities that further reduce their vulnerability and risk. This section first outlines the historical context for the macro-level framework, then briefly summarises the growing evidence base on the economic growth impact of social protection, and then illustrates how the development planning framework is increasingly influential in countries around the developing world.

Brazil pioneered the idea of 'complementary programmes' almost a decade ago, building explicit developmental linkages into social protection programmes in a manner that linked various instruments from different ministries across government (MSD 2007). Brazil's South-South capacity-building initiatives informed policy processes in both Ghana and Mozambique, which have worked to integrate this approach. In Ghana, as a result, the Livelihood Empowerment Against Poverty (LEAP) programme integrates social health insurance with cash transfers to mutually strengthen the different instruments. Mozambique's most recent cash transfer instrument aims to promote livelihoods of whole families by 'considering broader macro-economic areas for social investments to raise overall living standards (such as in agriculture, food security and employmentgenerating activities)' (UNICEF Mozambique 2011). The programme aims to link the different ministries that are currently responsible for various elements of social protection.

The development planning framework goes further, and integrates social protection instruments across different social and economic 


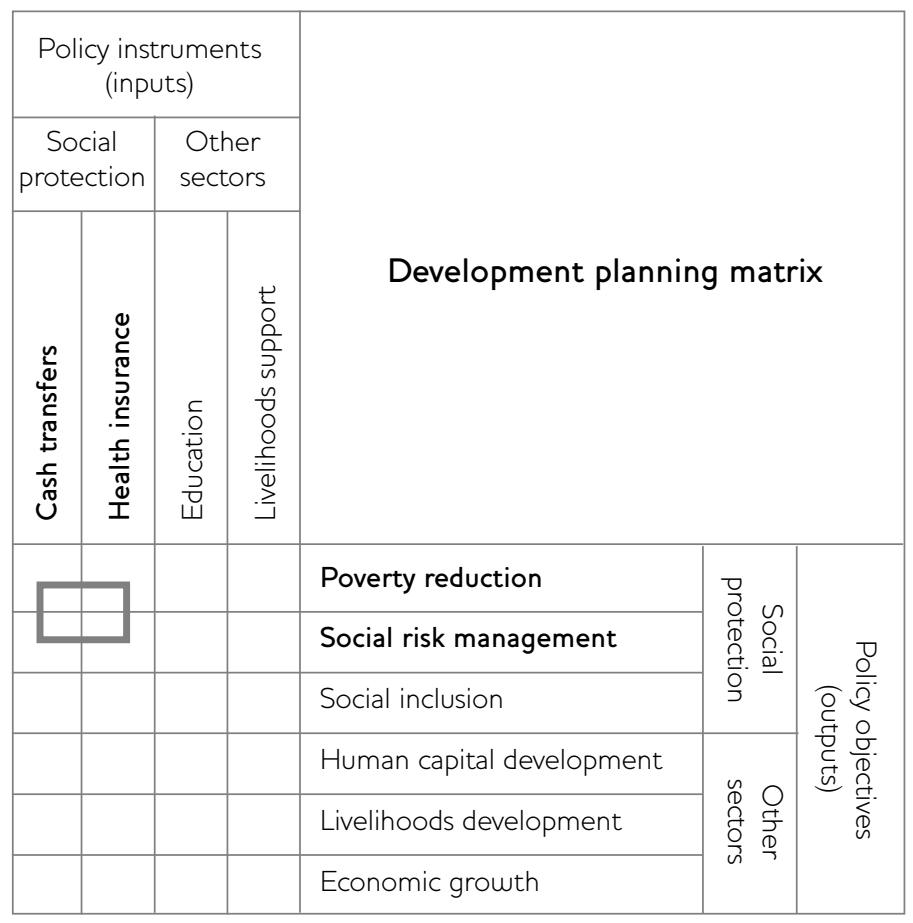

Source Author's own.

sectors, aiming to harmonise cross-ministerial approaches and build on intra- and inter-sectoral linkages. Countries as diverse as Bangladesh, Cambodia, Indonesia, Nepal, Rwanda, South Africa, Tanzania and Uganda are, in varying ways, employing the development planning approach to improve cross-cutting social and economic impacts. ${ }^{6}$

Within the framework, governments balance economic and social spending priorities, often perceiving an intensifying trade-off in times of economic downturn. The more policymakers understand the linkages between crisis impacts on the poor, and social protection and broader development priorities, the greater is their political will to implement effective interventions. Mobilising political will nevertheless remains one of the long-standing challenges in building national social protection systems. Global economic shocks provide an impetus for this political resource - because the political costs of inaction are high, and the global policy climate favours social protection responses. Ensuring that social protection interventions reflect the national social, institutional and policy context not only increases the likelihood of programme success but also reinforces political will. Credible monitoring and evaluation is also important for sustaining this political support.

The motivation for this development planning framework is the growing evidence base documenting the cross-sectoral impacts of social protection, particularly in terms of strengthening pro-poor and inclusive economic growth and development. In 2009 the OECD-DAC's Povnet published a volume of evidence documenting the broad social and economic development impacts of social protection, demonstrating the linkages with pro-poor and inclusive economic growth (OEGD 2009). Other publications have corroborated the key findings of this study: that social protection, through a number of transmission mechanisms, promotes human capital and other productive investment, strengthens households' abilities for productive risk-taking, provides opportunities for livelihoods development and employment, increases national economic resilience, promotes social cohesion and builds opportunities for pro-poor economic reforms. This approach to crosssectoral provision of development instruments is emerging in Mozambique, where in addition to 
cash transfers to labour-constrained individuals, the country has developed its social protection system by integrating inter-ministerial initiatives to promote livelihoods and employment by 'considering broader macro-economic areas for social investments to raise overall living standards (such as in agriculture, food security and employment-generating activities)' (UNICEF Mozambique 2011). In Ghana the LEAP programme integrates cash transfers with social health insurance to strengthen intrasectoral linkages (and the logic of this is illustrated in Figure 4).

This evidence base demonstrates that social protection operates through many pathways in delivering social and economic benefits. Most importantly, social protection aims to reduce poverty and vulnerability, and to protect people from shocks while directly supporting wellbeing. By protecting people from shocks social protection can prevent a further decline into poverty. Social protection enables poor households to preserve their productive assets and promotes high-return risk-taking that can help lift households out of poverty. An emerging evidence base is demonstrating how social protection interventions support employment and entrepreneurial activities. Combining social protection and labour market policies can produce a virtuous circle: social protection measures increase the employability of the poor, and labour markets that work better for the poor increase poor people's participation and remuneration. Evidence shows that social protection promotes development, not dependency.

Social protection generates economic gains not only for the poor, but for a wider segment of the population. Understanding the link between social protection and broader macroeconomic growth can increase stakeholder support for the reforms necessary to sustain long-term economic growth. Social protection also stimulates demand for local goods and services, promoting shortterm growth outcomes. Cash transfers inject liquidity into communities, spurring economic growth. Social protection represents one of the most concrete and valued forms of government delivery, strengthening social cohesion and promoting private investment. Social protection helps create an effective and secure state, promoting growth by building social cohesion and a sense of citizenship, as well as reducing conflict
(Samson et al. 2002; Bourguignon and Ravallion 2004; DFID 2005). Through the economic and developmental impacts listed above, social protection can help break the intergenerational transmission of poverty. During times of positive growth, social protection can translate to better circumstances for households facing hardship. During times of economic downturn, social protection acts as effective economic stimulus, both protecting the most vulnerable and jumpstarting economic recovery.

Social protection instruments - and social transfers in particular - provide one set of interventions that optimal policymaking would coordinate with other types of responses, particularly economic reforms and fiscal stimulus. The three types of responses have overlapping impacts - many social protection interventions produce pro-poor economic outcomes. Likewise, social protection interventions often provide effective fiscal stimulus, by increasing purchasing power for groups within society most likely to spend. Similarly, economic reforms and fiscal stimulus support their own as well as social protection objectives. Harmonised fiscal and economic policies better support pro-poor and inclusive economic growth, strengthening the potential of social protection to tackle poverty, risk and vulnerability while promoting developmental outcomes.

Increasingly, countries around the world are adopting national social protection strategies in order to better coordinate social transfers and other instruments. The goal of a national social protection strategy is to build a comprehensive social protection system that aims to tackle poverty, risk, vulnerability, exclusion and other social problems. This will promote human security and development, and contribute to pro-poor and inclusive economic growth.

\section{Building a national social protection strategy} involves national policy development, strengthening relationships within government and between government and other partners and an ongoing process of policy coordination. The development planning framework embeds the social protection strategy within the broader social and economic policy planning context. Figure 4 presents a proto-typical model that illustrates the process. 
The framework borrows an input-output matrix from the development planning models of the 1960s, but departs from the classic framework by defining 'inputs' as the range of government policies, programmes and instruments that enable the government to work to achieve 'outputs' - defined in this framework as the achievement of national policy objectives. Both the 'inputs' (strategies, programmes, instruments) and the 'outputs' can be organised sectorally in the matrix, in order to facilitate the coherence of the overall plan. The framework emphasises the importance of 'intra-sectoral' and 'inter-sectoral' linkages.

For example, intra-sectoral linkages within social protection reflect the efficiencies from producing comprehensive social protection approaches. As Figure 4 shows, cash transfers and social health insurance within the social protection sector demonstrate powerful intra-sectoral linkages. Catastrophic health shocks represent one of the main forces that can trap poor households into extreme poverty, notwithstanding the (small) cash transfers they might receive. Social health insurance excludes the poorest who lack the cash to pay the premiums required for participation. The combination of cash transfers and social health insurance works much better than the individual instruments on their own. Cash transfers enable households to finance the affordable premiums that characterise social insurance products, and sometimes programme officials make the participation decision for the entire beneficiary base - enrolling the entirety of cash transfer programme participants into the social health insurance scheme. Likewise, the social health insurance scheme protects poor households against severe medical shocks for which cash transfer programmes provide limited relief. The result of these intra-sectoral linkages is more effective social protection, which, amongst other things, helps protect the productive assets of the poor from distress sales in the face of catastrophic health shocks, preventing a decline into deeper poverty and sustaining stronger livelihoods.

Figure 4 also illustrates inter-sectoral linkages. Social protection instruments strengthen outcomes outside their own sector: deepening human capital, strengthening livelihoods development and broadly promoting pro-poor and inclusive economic growth. Many social protection instruments work by expanding poor people's access to markets. Cash transfers expand the effective demand for market goods and services, enabling poor men and women to meet their basic needs while stimulating economic activity. Likewise, a range of policy sectors can contribute to social protection objectives, including the long-term impact of livelihoods support instruments in reducing poverty and household vulnerability.

The essential element of the development planning framework for social protection is a national coordinating mechanism that plans, prioritises and integrates social protection policies and practices. This is often the National Development Plan, coordinated by a National Planning Commission (or similar authority). These integrated and comprehensive development planning approaches to social protection improve impact and value-for-money by maximising the likelihood of achieving the critical policy objectives while minimising risks and costs. In addition, practical development plans reinforce credibility in the government's strategy, enabling the government to expand its policy options.

\section{Linking micro-level design with macro-level factors: aiming for the dynamic deepening of developmental impact with a graduation approach}

Social protection's chief aims are to effectively reduce poverty, vulnerability and social exclusion. The framework developed in this article, however, illustrates how social protection with a developmental approach can work with both micro and macro linkages to deepen socioeconomic impact at individual and household level. By strengthening virtuous circles, this micro-macro approach can sustainably promote dynamic outcomes, with inclusive economic expansion reinforcing poverty reduction, which in turn contributes to further growth and development.

There is no magic bullet. Applying the lessons of success from micro-oriented developmental programmes to developing countries around the world requires substantial additional work in terms of (1) identifying what accounts for success in existing programmes, and (2) determining what design features are most important for the individual country contexts to 
which these models can be applied. And these are just the first steps - implementation models pose a number of further important challenges.

These micro-oriented initiatives will likely work best when embedded within a broader macro development framework that integrates and strengthens the range of social and economic policy instruments implemented by government. The contribution of the macro environment is difficult to quantify rigorously - randomised controlled trials are neither practical nor appropriate for national development approaches (you cannot randomise countries), so attribution of impact poses challenges. The important role for the national planning function to coordinate and integrate social protection policies and programmes in an increasing number of developing countries indicates the perceived importance by policymakers of the macro linkages.

This suggests a way forward for countries that want to maximise the pro-poor and inclusive growth and development impacts by incorporating developmental graduation

\section{Notes}

* This article builds on work originally commissioned by AusAID. The views expressed are those of the author.

1 African Union Ministerial on Social Protection (2006), Livingstone, Zambia, conference organised by HelpAge International that led to the Livingstone Declaration. One of the field visits organised by the conference involved a report of this case.

2 The phrase 'graduation without exit' was used to characterise this developmental approach at the Ford/CGAP meetings in Cartagena (2013), Rio (2013) and Paris (2014).

3 This index measures the number of developmental criteria characterising a beneficiary household, measuring assets, livelihoods, human capital, empowerment and other dimensions. BRAC created the index based on their research and experience working to enable extremely poor households to lift themselves out of poverty. components within national social protection strategies. The first step is to plan social protection policies and instruments within a cross-cutting development framework that maximises both intra-sectoral and inter-sectoral linkages. This enables the social protection programmes to reach beyond their core objectives of tackling poverty, vulnerability and social exclusion and strengthen other developmental sectors. The second step is to adopt an evidenceinformed approach to designing social protection programmes for developmental impact - drawing from the global lessons of successful experience in the light of integrated evaluation approaches, but carefully rooting appropriate programmes within the country's specific context. This strengthens the specific instruments in achieving developmental impact. Subsequent steps - not addressed in this article - include ensuring that well-designed implementation systems contribute to the developmental objectives, and ensuring that effective monitoring and evaluation build the evidence base for successful scale-up. This micro-macro integrated approach offers the potential to dynamically deepen developmental impact.

4 These include the Government of Bangladesh/UNDP's REOPA model, which emphasises the role of savings through a public works model. The Chars Livelihoods Programme (CLP), funded by AusAID and DFID, adopts a model similar to the CFPR programme in the challenging char regions. The International Labour Organization (ILO) has implemented a model (Community-based Training for Economic Empowerment programme) with a greater focus on training, with a high degree of success.

5 Reported at the Fundación Capital workshop in Cartagena June 2012 and the Ford/CGAP meeting in Paris July 2012, with further details documented at http://graduation.cgap.org/research.

6 Bangladesh is beginning to employ the development planning framework for social protection. Other case studies are being prepared to further illuminate how different countries embrace the model. 


\section{References}

Bourguignon, F. and Ravallion, M. (2004) Social Protection and Economic Growth, London: Department for International Development (DFID)

Das, Narayan C. and Shams, Raniya (2011) Asset Transfer Programme for the Ultra Poor: A Randomized Control Trial Evaluation, GFPR Working Paper 22, Dhaka: BRAC

DFID (2005) Social Transfers and Chronic Poverty: Emerging Evidence and the Challenge Ahead, DFID Practice Paper, London: Department for International Development

Garcia, M. and Moore, C. (2012) Cash Dividend: The Rise of Cash Transfer Programs in Sub-Saharan Africa, Washington DC: World Bank

MSD (Ministry of Social Development, Brazil) (2007) Presentation at the course 'Designing and Implementing Social Transfer Programs', 22 July-3 August, EPRI, Cape Town

OECD (2009) Social Protection and Pro-poor Growth, Paris: OECD

Sabates-Wheeler, R. and Devereux, S. (2013)

'Sustainable Graduation from Social
Protection Programs', Development and Change 44.4: $911-38$

Samson, M. (2013) 'How are Countries Using Social Protection to Benefit the Poor?', in Development Co-operation Report 2013: Ending Poverty, Paris: OECD

Samson, M. (2012) Presentation at the Fundación Capital workshop 'Graduation in Public Policy: Constructing a Regional Working Agenda', Cartagena, Colombia, 28-29 June

Samson, M.; Babson, O.; Haarmann, C.; Haarmann, D.; Khathi, G.; Mac Quene, K. and van Niekerk, I. (2002) Social Security Reform and the Basic Income Grant for South Africa, report commissioned by the ILO, Gape Town: Economic Policy Research Institute

UNICEF Mozambique (2011) 'Strengthening and Scaling Up of the Social Protection System: Part 1', Media Centre, 5 September, www.unicef.org/mozambique/media_9455.html (accessed 14 January 2015) 